\title{
The Reflection of Vocabulary Implementation Through Educational Texting on EFL Learner's Reading Skill
}

\author{
https://doi.org/10.3991/ijim.v15i01.18309
}

\author{
Behnam Behforouz $^{(\varpi)}$, Anca Daniela Frumuselu \\ University of Rovira i Virgili, Catalunya, Spain \\ behnam.behforouzdestudiants.urv.cat
}

\begin{abstract}
This paper investigates the efficiency of text messaging in the English as a foreign language (EFL) reading classroom at the Islamic Azad University-South Tehran Branch, Iran. After administration of an Oxford Placement Test (OPT), 74 participants who scored between \pm 1 standard deviation of the mean were randomly assigned to an experimental and a control groups, with 37 individuals each. The reading part of the Preliminary English Test (PET) was administered as a pretest. The experimental group received 108 words via short messages in 18 sessions. During each session, they received 6 sentences with 6 words in a meaningful context. In contrast, the control group received traditional instruction. They were given the same structural points through inductive and deductive instruction in the classroom, and the words were presented while teaching each unit. After finishing the treatment procedure, the students in both groups were assigned to do a reading posttest. The results of the ANCOVA revealed no meaningful discrepancy between both groups based on the reading scores. Thus, vocabulary learning via short messages did not affect Iranian EFL learners`ability to comprehend pre-intermediate level texts.
\end{abstract}

Keywords - Vocabulary learning, texting, English foreign language learning, reading comprehension

\section{Introduction}

In reading comprehension, readers need to understand the text to gather some information or to perform activities with the received information. As [1] states, reading is beyond knowing what each letter of the alphabet stands for, and it deals with more than word recognition. Rather, reading needs critical thinking for interpretation. Based on [2], reading is difficult to analyze since it deals with the most complex working of the human mind; it is a real cognitive process. Put differently; reading is printed thinking. Reading comprehension is generally regarded as a basic requirement for foreign language (FL) learners' academic success. Often L2 proficiency considers grammar and vocabulary as the knowledge part of text understanding, while reading can be seen as a type of ability for this purpose [3]. Studies regularly confirmed that knowledge of vocabulary is highly related to reading comprehension rather than various other aspects like grammatical knowledge [4], [5]. According to [6], without understanding the 
vocabulary of the text in L1 or foreign language, content comprehention is impossible. Consequently, without understanding the meaning of the words, L2 readers may experience difficulty improving comprehension. Therefore, vocabulary seems a significant factor in reading comprehension [7].

Learning vocabulary is a basic step in learning a foreign language. Hence, a large amount of studies has been conducted to enhance vocabulary learning efficacy [8], [9], [10], [11], [12], [13], [14], [15], [16]. Despite several studies carried out on vocabulary learning, students use significantly lower percentage of their efforts to solve their issues when acquiring new vocabulary [17]. During class time, teachers and instructors mostly tend to have an attitude toward involving learners with this problem outside the classroom with their own responsibilities [18]. However, students lack knowledge regarding the effective techniques of vocabulary learning, and have difficulty finding good strategies [8]. Using mobile technologies to support the learning process has become familiarized with the improvement of 21st-century skills [19], [20], [21], [22].

This application of technology provides a solution for FL learners to emphasize the authentic function of language. Mobile-assisted language learning (MALL) is a relatively new learning instrument that learners use with great potential to receive instruction any time and anywhere for L2 classes. Also, the accessibility of mobile phones in Iran has been rapidly extended to different generations, so that information technology can generally increase opportunities for improving learners' English skills despite their age. It should be noted that MALL provides the opportunity to use a personal portable device to enhance learning regardless of time and place [23].

There is an increase in the application of mobile tools for educational objectives and also for personal use all over the world [24]. Indeed, technical devices such as laptop computers and smartphones have revolutionized education and transformed traditional classroom-oriented instruction into anywhere and anytime education [25].

Even with the growth of reliable and trustworthy technological instruments and the accessibility of computers in Iranian universities and language institutes, as well as the increasing confirmation of blended teaching effectiveness, a large number of Iranian EFL teachers are not enthusiastic about applying such instruments in their EFL classes. As [26] stated, teachers' skills, knowledge, and opinions about the fruitfulness of instructional technology and the influential implementation of resources are reasons why teachers do not use digital technology when teaching languages.

The purpose of this paper is to use text messaging as an educational instrument to measure Iranian EFL learners' reading abilities to comprehend B1-level (pre-intermediate) texts. Sending and receiving SMS as a trustworthy and popular communication system among its users is a trendy instrument for communication worldwide. It has been viewed by studies as a proper and convenient instrument for educational purposes [27], [28], [29].

In the following sections, some major studies regarding the mobile phone in learning will be investigated. Then the methodology of the present study will be presented followed by a discussion, and finally, the conclusion of the study with some recommendations will be stated. 


\section{$2 \quad$ Literature Review}

This part deals with the explanation of different studies conducted to discover the effect of mobile phones application on an instructional environment. Additionally, it will present different researchers' views on the effect of mobile devices in the instructional environment. Different factors affect the L2 learning process, such as input, the context, learner's first language, and even technology.

\subsection{Mobile learning}

Mobile-learning and m-learning are improvements to electronic learning (e-learning) [30], [31] as they integrate e-learning and mobile computing, which point out the advantages of mobile technologies, such as the latest generation of mobile phones and tablets and their related applications (apps) [21], [32].Without a doubt, justifying students' needs in English learning, MALL is the next stage of educational technology improvement, indicating the digital convergence of e-learning and mobile technology in reaction to a more dynamic and active society that looks for a personalized, longlasting universal education [33]. Positive attitudes or perceptions towards MALL in higher education have been realized in various studies [34], [35], [36], [37], [38], [39], [40]. As a result, MALL seems to have preserved its position in teaching and learning foreign languages, and its place may be more dominant in the future.

Although [41] believe that learning through mobile phones can be considered as a modern occurrence, but the impact of such an instrument on educational learning can be considered endless. In addition, according to [42], MALL is rapidly developing as students can use them in various places at at their convenient time, in the absence of any supervisor, which makes them independent learners. Such a capability is an advantage in that the experience of independence can motivate learners to keep on learning for future goals [43].

[44] stated that mobile learning can make the design of authentic learning possible. This kind of learning is advantageous for learners who cannot attend language institutions because of their jobs, chores, and various things that need time [45]. Different studies have been carried out on the application of social media programs like Facebook (e.g., [46], [47]) and Twitter (e.g., [48], [49], [50]) in classrooms.

In a study by [51], the implementation of a didactic approach in a high school was initiated by teachers of environmental education through mobile phones and QR codes. Consequently, mobile technology in the environmental education program significantly affected the improvement of learners' knowledge considering environmental issues and the local flora and fauna.

\subsection{The effects of SMS on educational context}

SMS is the text messaging service part of most telephones, mobile device systems, and the Internet. It uses standardized communication protocols to provide mobile devices with the capability to exchange short text messages. Therefore, no student can be 
seen without a mobile phone. It happens in two situations: either the person is waiting for a reply from someone, or he is sending some messages to the other. Thus, learners have used text messages to generate virtual contexts, as well as opportunities to socialize [52]. Accordingly, learners consider text messaging as a routine activity [53].

SMS can be considered as a modern technique that is applicable in the present educational context, and it can improve educational processes in various fields of study [54]. [55] believes that implementing educational SMS which deals with syntactical structures facilitates sentence paraphrasing in English classes. He also stated that teachers can use SMS as an instructional medium to teach all the required skills at their convenient time because of a lack of adequate teaching hour in the class. He argued that students who receive learning materials through SMS are more eager and motivated than other students. Since sending and receiving information using SMS is cheap, quick, and affordable, learners see it as a convenient way to communicate information [56].

In an EFL context, lexical competence can be regarded as a major skill to better L2 comprehension, and it can rarely be denied that learners' vocabulary knowledge is highly associated with their reading comprehension as well as their overall academic success [57]. In recent years, researchers have attempted to find solutions for questions dealing with the kind of most effective vocabulary instruction to help students learn new words and understand what they have read [58], [59], [60], [61].

Recently, much space in the research has been devoted to teaching vocabulary because it plays a vital role in language teaching and learning, particularly about communication. A high number of robust studies have been done on vocabulary instruction, and many of them have stated that it is impossible to teach all vocabulary a learner should know [62], [63], [64]. However, a reader needs to recognize at least $95 \%$ of the surrounding words to comprehend a text [65]. This problem can be solved by using mobile-assisted instruments as effective ones in teaching and learning.

As can be observed, the theoretical framework of the current paper has tried to implement educational texting via mobile phone as a medium to implement vocabulary instruction among higher education students and to measure their ability to understand pre-intermediate level texts.

\section{Method}

The current study intends to measure Iranian EFL learners' competence in comprehending pre-intermediate-level material after texting them some vocabulary items. To this end, a quasi-experimental design wasimplemented including tests before and after the treatment. Later, the procedure including sampling, instrumentation, data collection, and data analysis will be explained in the following section.

\subsection{Participants}

A total of 88 university students with different majors (Chemistry, Civil Engineering, Computer Science, and Electrical Engineering) studying general English at the 
Islamic Azad University-South Tehran Branch, Iran participated in this study voluntarily. To measure the their general English proficiency and ensure their homogeneity, the Oxford Placement Test (OPT), was administered. Afterward, homogenous students were selected as the study sample. It should be mentioned that the students covered a reading comprehension course within the semester. They were randomly divided into an experimental group and a control one, with 37 each.

\subsection{Instruments}

Various tools were used to collect the required data as follows. OPT was conducted to measure the learners' ability to communicate in English. This test includes 60 items with two parts: grammar, reading and vocabulary. The dependent variable was measured with the Preliminary English Test (PET). This test was administered as the pretest and posttest and includes five parts: Three-option Multiple Choice, Matching, True/False, Four-option Multiple Choices, and Multiple-Choice Cloze.

OPT rankings are shown in Table 1. The population of the current paper was selected based on learners' lower-intermediate scores; thus, all students who scored between 28 and 36 points were considered viable participants for the present research.

Table 1. Oxford Placement Test ranking

\begin{tabular}{|c|c|c|c|c|c|}
\hline Beginners & Elementary & Lower-Intermediate & Upper-Intermediate & Advanced & Very Advanced \\
\hline $1-17$ & $18-27$ & $28-36$ & $37-47$ & $48-55$ & $56-60$ \\
\hline
\end{tabular}

Due to the policy of the Islamic Azad University-South Tehran Branch, the General English Book: A Task-Based Approach written by [66] must be used as the coursebook for reading comprehension. This book contains nine lessons with color photos and tables. Only the first five lessons were taught during this semester. Each lesson covers different types of reading strategies such as guessing, scanning, skimming, reading a table, summarizing a text, etc.

The researchers used SMS to send vocabulary content. Since the focus of this study was on the use of mobile phone technology to measure learners' reading comprehension, students in the experimental group use this tool to receive SMS as treatment. The total number of SMSs were 18 messages for six weeks of treatment. The vocabulary items and their examples were within sentences so that the students can easily read the messages on their small screens. The delivery reports of the mobile phones were controlled to remove the possible failure of the system. Below are sample SMSs sent to the learners' mobile phones on the fourth and fifth weeks of the project (see Figures 1 and 2 in the Procedure section).

\subsection{Procedure}

The present study was conducted during the fall semester of the 2019-2020 academic year over an 18-session treatment during six consecutive weeks (the participants in the experimental group would receive SMSs three times a week). It should be mentioned 
that the first and the last sessions were devoted to the administration of the PET pretest and posttest, respectively. The same teacher taught both groups. The researcher used SMS to measure the improvement or lack of it in learners' reading comprehension by implementing vocabulary via SMS. To complete the process of collecting data, the researcher went through several procedures.

First, to ensure participants' homogeneity, an OPT was administered to 88 students studying at the Islamic Azad University-South Tehran Branch. Seventy-four participants, based on their OPT scores, were placed in the pre-intermediate level and were randomly assigned to two groups (experimental and control). The next step was the administration of the PET reading test as a pretest to assess participants' prior knowledge of ability in reading comprehension. After the administration of the pretest, the treatment procedure took place.

The vocabulary list was delivered to the experimental group via SMS, six items per SMS three times a week. They received SMSs, including vocabulary items, for 18 sessions in 6 weeks. Each word was used in one short sentence, with a synonym and a single word Persian translation at the end of the sentence in parenthesis. The SMSs were delivered to the group of 37 learners at once. Figure 1 shows the $12^{\text {th }}$ lesson of the fourth week. These items were selected from the coursebook and sent to all 37 learners in the experimental group.

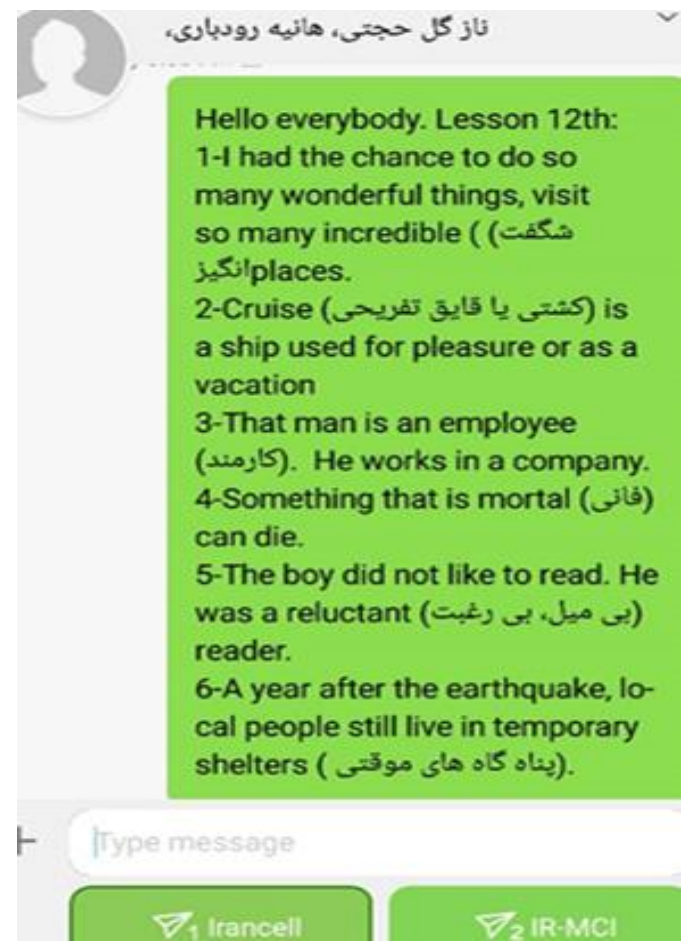

Fig. 1. Lesson 12, Week 4 


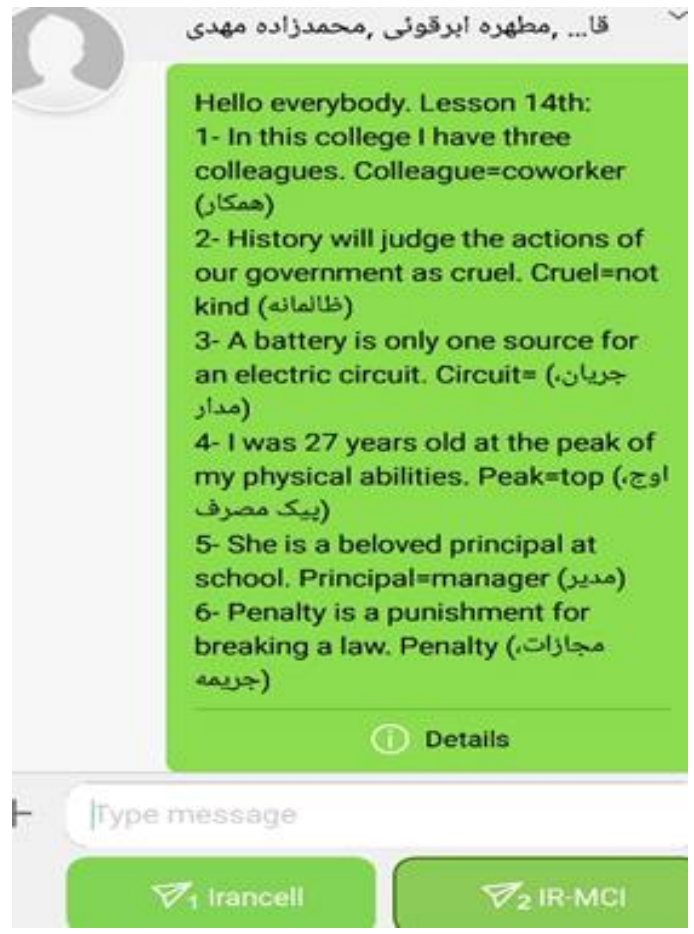

Fig. 2. Lesson 14, Week 5

Figure 2 shows the vocabulary item from week 5 . All the participants in the experimental group received the lesson. The items were selected from the coursebook.

In contrast, the control group received the traditional instruction, i.e., they were given the same items through inductive and deductive instruction in the classroom, and the words were presented while teaching each unit. At the end of the experiment, the PET reading test was administered as a posttest to both groups to assess the participants' scores and the effectiveness of the treatment procedure.

\subsection{Data analysis and findings}

This part concerns the presentation, analysis, and interpretation of data collected over six weeks at the Islamic Azad University-South Tehran Branch. After collecting the data from the research instruments, descriptive analysis was carried out focusing on the basic features of the data, and inferentially, trying to reach conclusions that extend beyond the immediate data alone. To investigate EFL learners' reading comprehension ability when they were exposed to increased vocabulary using SMS via mobile phones, the Statistical Package for Service Solution (SPSS) program was used. To this end, covariance (ANCOVA) was employed to compute the mean discrepancies between both groups. 
To check if the sample is homogenous in terms of their general English proficiency level, an OPT was given to the initial sample. After the OPT, 74 out of 88 participants were considered homogenous learners according to their scores, ranging from 28 to 36 (pre-intermediate level). Table 2 shows that the mean and the standard deviation of the participants are 31.66 and 2.22, respectively. It also shows that the selected participants are homogenous regarding their ability to communicate in English.

Table 2. The descriptive statistics of the homogenized participants

\begin{tabular}{|l|c|c|c|c|c|c|}
\hline & N & Min & Max & Mean & Std. Deviation & V \\
\hline Homogenized & 74 & 28.00 & 36.00 & 31.662 & 2.228 & 4.966 \\
\hline Valid N (listwise) & 74 & & & & & \\
\hline
\end{tabular}

The study sought to investigate whether vocabulary implementation could affect Iranian EFL learners' ability to comprehend pre-intermediate level texts. To delve into this aspect, an ANCOVA test was implemented. In Table 3 below, the mean for both groups, control and experimental, in terms of reading scores are 21.40 and 22.86, respectively.

Table 3. The descriptive statistics for the adjusted reading scores of the two groups

\begin{tabular}{|l|c|c|c|c|}
\hline \multirow{2}{*}{ Group } & & \multirow{2}{*}{ Mean } & Std. Error & \multicolumn{2}{c|}{ 95\% Confidence Interval } \\
\cline { 4 - 5 } & $21.403^{\mathrm{a}}$ & .693 & Lower Bound & Upper Bound \\
\hline Control & $22.867^{\mathrm{a}}$ & .693 & 20.021 & 22.785 \\
\hline Experimental & \multicolumn{3}{c}{} \\
\hline
\end{tabular}

The ANCOVA results can be seen in Table 4 below, in which, the pre-scores variable is the covariate. When we include a covariate, we have more than one effect, and we could calculate eta squared for each effect.

Table 4. The result of the ANCOVA for the comparison of the reading scores

\begin{tabular}{|l|c|c|c|c|c|c|}
\hline \multicolumn{1}{|c|}{ Source } & Type III Sum of Squares & Df & Mean Square & F & Sig. & Partial Eta Squared \\
\hline Corrected Model & $1067.233 \mathrm{a}$ & 2 & 533.616 & 30.035 & .000 & .458 \\
\hline Intercept & 559.429 & 1 & 559.429 & 31.488 & .000 & .307 \\
\hline Pre_Scores & 1041.071 & 1 & 1041.071 & 58.598 & .000 & .452 \\
\hline Group & 39.622 & 1 & 39.622 & 2.230 & .140 & .030 \\
\hline Error & 1261.416 & 71 & 17.766 & & & \\
\hline Total & 38586.000 & 74 & & & & \\
\hline Corrected Total & 2328.649 & 73 & & & & \\
\hline
\end{tabular}

As Table 4 shows, there is no huge discrepancy between both groups in terms of reading scores, $F(1,71)=2.23, p>.05$, partial $\eta^{2}=.03$. The partial Eta Squared value is used to define the amount of variance in the dependent variable (vocabulary increment) by the independent variable (learners' reading comprehension) $(0.3 \%)$, which is considered trivial. Therefore, vocabulary implementation did not affect Iranian EFL learners' ability to comprehend pre-intermediate level texts. It is worth noting that 
sample size decreases the statistical power of the study and increases the margin of error, which can interpret the study meaninglessly.

To measure learners' perceptions toward mobile assisted language learning, an interview session with the experimental group was conducted with some researcher-made questions and the results revealed that students are interested in using mobile phones in academic exposures (study is under process for publication).

\section{Discussion}

The current research intended to measure the impact of vocabulary implementation using SMS on Iranian EFL learners' ability to comprehend pre-intermediate level texts. In this regard, a pretest was used to understand their reading comprehension, and the results confirmed that both the control and experimental groups have a similar level of understanding in terms of reading skills. To measure the effects of treatment, which was receiving vocabulary through SMS, another reading test was conducted as a posttest, and its results were compared with those of the pretest. The results showed that although the experimental group gained better scores, the difference was not academically significant. This means that in the design of the current study, with 74 participants and perhaps with 108 vocabulary items given to students each week, the results were not statistically significant. The findings of the current study showed that Iranian EFL students could not display positive performance in understanding pre-intermediatelevel texts. It seems that vocabulary seems is not the only factor that affects reading ability.

The results of the current research are compatible with those of a few empirical studies. [67] reported that sending more than three texts a day tended to results in lower scores in literacy tests than when they were not sent. The findings are supported by those reported by [68]. They investigated the impact of texting on ESL learners at Aligarh Muslim University. The findings revealed negative effects of texting on ESL learners. [69] stated that text messaging could have a negative influence on learners' spelling. [70] asserted that the negative effect of using text messaging on English literacy reduces formal writing, affects speaking skills, and damages grammatical skills, creating some confusion in the spelling of words. [71] also suggested that students are unable to distinguish informal and from formal contexts and use texts at the wrong time. [72] also found out that the SMSs of primary and secondary school learners were full of grammatical issues. Indeed, these students made more capitalization and punctuation errors and used unconventional punctuation more than adult learners, when the length of their messages was considered.

The findings of this study are consistent with those by [73] who attemptted to determine the role of MALL on EFL learners' writing accuracy, fluency, and complexity. The results indicated that although the writing fluency and complexity of the experimental group improved in comparison with their control peers, the accuracy aspect followed a reverse pattern.

The findings of the current paper also have similarities with the results of a study done by [74] who found that smartphones delivered negative results on the academic 
performance of university students. The results also agree with the findings of [75], which showed no difference between the experimental and control groups in listening and pronunciation courses. However, the findings of this study are not consistent with those by [76].

However, the findings are not in line with the results reported by [12], which showed that the integration of the teacher training program and vocabulary instruction applications was successful and effective. This study's results also disagree with those of the study by [77], which aimed to discover the effect of texting to improve academic vocabulary learning. The findings emphasized learners' positive experience with the treatment, the feasibility of the treatment design, and its impact in supporting English language learners' vocabulary study.

In addition, the results here are not consistent with those presented by [78]. She revealed that mobile learning through text messaging could improve learners' vocabulary knowledge and help them acquire L2 words more consistently. The results of the current study are also against those of a study by [25], which focused on students' positive attitudes toward learning vocabulary through mobile phones. This study is also in disagreement with the results of [79], who examined the effectiveness of mobile learning by sending technical words and meaningful sentences for ESP learners every day for three weeks. Their findings showed that students learned the words in a motivated, enjoyable, and effective way. The present results also are not consistent with those reported by [80], which indicated learners' positive attitude toward the use of SMS for learning and the use of their own mobile devices as a learning instrument. Learners revealed their interest in receiving pedagogical content through SMS. Some learners greatly enhanced their language learning performance.

[81] discovered that vocabulary programs of mobile phones improve vocabulary gain and enhance learner motivation. [82] reported similar findings. [82] showed that mobile phone users received greater achievement in a word knowledge test, and developed a positive attitude toward mobile phone application. The results are not also in accordance with findings by [83], who stated that mobile phones can be an influential medium for self-learning L2 vocabulary.

Although the current study reached its objectives, there were some inevitable limitations. First, because of the small sample size, the results may not be generalizable for the considered population. Second, learners' motivation, aptitude, affective, and attitudinal parameters were not taken into account. A further study can be carried out by examining these parameters. Third, the focus of the present study is on reading skill, and other skills were not considered; thus, a further study investigate other skills such as writing, speaking, and listening. Fourth, only pre-intermediate level learners took part in this study, so another study may focus on learner's various language proficiency levels. Fifth, the focus of this study was limited to sending SMS to improve learners' vocabulary knowledge, so additional goals could be added for a more in-depth view of the group's tendencies when they are in contact with this type of educational tool.

Additionally, more qualitative analyses are needed in these types of studies to grasp not only learners' performance but also their response to the application of SMS as an educational instrument in the EFL classroom. 


\section{Conclusion}

The present study was a short, six-week investigation at Azad University-South Tehran Branch. It has extended the existing body of literature that investigates the effect of vocabulary increments through mobile phone text messaging on learners' ability to comprehend B1-level texts. As the findings of this study showed, although SMSs can be easily sent at pre-scheduled times and intervals, can be saved systematically, and are available for later retentions, they could not facilitate certain forms of learning. This can be because newly learned vocabulary items are only weakly acquired. As these vocabulary items are held in one's working memory for a short time, they could not be part of the linguistic system of the students. When there is no repeated exposure to vocabulary, they can be easily removed from learners' working memory. Whenever new words are integrated into learners' long-term memory, they can be tightly attached to a network of ideas, words, and concepts that the brain can access effortlessly [84].

Using mobile phones in EFL contexts does not always result in positive effects on academic performance. Although smartphones may substantially improve the foreign language learning process, several studies have highlighted certain limitations to use smartphones in higher education contexts. One of these pitfalls is smartphone addiction, which is being increasingly investigated by researchers worldwide. It can be concluded that smartphones must be used appropriately, with sufficient preparation and clear objectives in mind. It is worth noting that teachers all over the world are provided with adequate and influential training to implement MALL appropriately and effectively. Therefore, research on MALL and the use of SMS is still in its infancy. There is undoubtedly a need to conduct a tremendous amount of research to clarify the details of this subject.

The results of this study cannot be generalized as the number of participants and the amount of data are not broad. More accurate and generalizable results would be achieved if the framework of the study was more general. The study recommends further investigation on the effect of SMS on other skills such as writing practices. In summary, a deeper and more comprehensive understanding of the subject under investigation can be accomplished by conducting a qualitative analysis to reveal the depths of such a subjest and to have a broader vision of the current results.

\section{References}

[1] R. I. Dallman, Teaching of reading. New York: CBS College Publishing, 1982.

[2] F. Kurniasih, A. Murweni, Mahpul,"The implementation of think-pair-share technique in improving students' reading comprehension," UNILA Journal of English Teaching, 6 (2), 2017.

[3] K. Koda, Insights into second language reading: A cross-linguistic approach. Cambridge: Cambridge University Press, 2005. https://doi.org/10.5785/24-2-46

[4] K. Koda, "The effects of transferred vocabulary knowledge on the development of L2 reading proficiency," Foreign Language Annals, 22, 529-540, 1989. https://doi.org/10. 1111/j.1944-9720.1989.tb02780.x 
[5] D. Qian, "Assessing the roles of depth and breadth of vocabulary knowledge in reading comprehension," The Canadian Modern Language Review, 56, 282-308, 1999. https://doi.org/10.3138/cmlr.56.2.282

[6] B. Laufer,"The lexical plight in second language reading: Words you don't know, words you think you know, and words you can't guess," in Second Language Vocabulary Acquisition, J. Coady and T. Huckin, Eds. Cambridge: Cambridge University Press, 1997, pp- 2034. https://doi.org/10.1017/cbo9781139524643.004

[7] J. C. Richards, and T.S. Rogers, Approaches and methods in language teaching (2nd ed.). Cambridge, UK: Cambridge University Press, 2001.

[8] A. Akın, and G. Seferoğlu, "Improving learners' vocabulary through strategy training and recycling the target words," Hacettepe University Journal of Education, 27(1), 1-10, 2004.

[9] A. Bruton,"Vocabulary learning from dictionary reference in collaborative EFL translational writing," System, 35(3), 353-367, 2007. https://doi.org/10.1016/j.system.2007.01.004

[10] I. H. Erten, and M. Tekin,"Effects on vocabulary acquisition of presenting new words in semantic sets versus semantically unrelated sets," System, 36(3), 407-422, 2008. https://doi.org/10.1016/j.system.2008.02.005

[11] B. Genç,"New trends in teaching and learning vocabulary," Çukurova Üniversitesi Sosyal Bilimler Enstitüsü Dergisi, 13(2), 117-126, 2004. https://doi.org/10.35379/ cusosbil.556866

[12] M. A. M. Kassem, "The effect of a suggested in-service teacher training program based on MALL applications on developing EFL students' vocabulary acquisition," Journal of Language Teaching and Research, 9(2), 250-260, 2018. https://doi.org/10.17507/jltr. $\underline{0902.05}$

[13] J. MCCarten, Teaching vocabulary : Lessons from the corpus, lessons from the classroom. Cambridge University Press, 2007.

[14] S. Moras,"Teaching vocabulary to advanced students: A lexical approach," seasite.niu.edu, July, 2001. [Online]. Available: http://www.seasite.niu.edu/Tagalog/Teachers_Page/Language_Learning_Articles/teaching_vocabulary_to_advanced_.htm.

[15] J. Newton,“Options for vocabulary learning through communication tasks,” ELT Journal, 55(1), 30-37, 2001. https://doi.org/10.1093/elt/55.1.30

[16] E. Tang, and H. Nesi, “Teaching vocabulary in two Chinese classrooms: Schoolchildren's exposure to English words in Hong Kong and Guangzhou," Language Teaching Research, 7(1), 65-97, 2003. https://doi.org/10.1191/13621688031r113oa

[17] P. Meara,"Vocabulary acquisition: A neglected aspect of language learning," Language Teaching and Linguistics, 13(4), 221-246, 1980. https://doi.org/10.1017/s026144 $\underline{4800008879}$

[18] G. Baykal, and A. Daventry, "Vocabulary for interacting with," In Proceedings of the 5th METU international ELT convention: Interaction on the threshold of a new millennium, 2000, pp. 168-173.

[19] S. Henderson, and J. Yeow, "iPad in education: A case study of iPad adoption and use in a primary school," In 45th Hawaii International Conference on System Sciences, 2012, pp. 78-87. https://doi.org/10.1109/hicss.2012.390

[20] C. L. Lai, and G. J. Hwang, "Effects of mobile learning time on students' conception of collaboration, communication, complex problem-solving, meta-cognitive awareness and creativity," International Journal of Mobile Learning and Organisation, 10 (3), 276-291, 2014. https://doi.org/10.1504/ijmlo.2014.067029

[21] S. Papadakis, M. Kalogiannakis, and N. Zaranis, "Developing fundamental programming concepts and computational thinking with scratch in preschool education: A case study," 
International Journal of Mobile Learning and Organisation, 10 (3), 187-202, 2016. https://doi.org/10.1504/ijmlo.2016.077867

[22] N. Zaranis, M. Kalogiannakis, and S. Papadakis, "Using mobile devices for teaching realistic mathematics in kindergarten education," Creative Education, 4 (7), 1-10, 2013. https://doi.org/10.4236/ce.2013.47a1001

[23] M. J. De la Fuente, "Learners' attention to input during focus on form listening tasks: The role of mobile technology in the second language classroom," Computer Assisted Language Learning, 27(3), 261-276, 2014. https://doi.org/10.1080/09588221.2012.733710

[24] L. Ducate, and L. Lomicka,"Podcasting in the language classroom: Inherently mobile or not?" in Second language teaching and learning in the next generation, R. Oxford and J. Oxford, Eds. Honolulu: University of Hawai'i, National Foreign Language Resource Center, 2009, pp-113-128. https://doi.org/10.1017/s0272263110000677

[25] N. Cavus, and D. Ibrahim, "M-learning: An experiment in using SMS to support learning new English language words," British Journal of Educational Technology, 40 (1), 78-91, 2009. https://doi.org/10.1111/j.1467-8535.2007.00801.x

[26] M. Dellicarpini,“Action research: building computer technology skills in TESOL Teacher Education,” Language Learning \& Technology, 16 (2), 14-23, 2012.

[27] A. Kukulska-Hulme, and L. Shield, “An overview of mobile assisted language learning: From content delivery to supported collaboration and interaction," RECALL, 20 (3), 271289, 2008. https://doi.org/10.1017/s0958344008000335

[28] L.L. Lominé, and C. Buckhingham,"M-learning: texting (SMS) as a teaching \& learning tool in higher arts education," European League of Institutes of the Arts Teachers' Academy, $1-6,2009$.

[29] J. Traxler,"Case studies: Introduction and overview," In Mobile Learning: A handbook for educators and trainers, A. Kukulska-Hulme and J. Traxler, Eds. London: Routledge, 2007, pp- 86-91. https://doi.org/10.4324/9780203003428

[30] M. Singhal, “The internet and foreign language education: Benefits and challenges," The Internet TESL Journal, 3(6), 1997. [Online serial] Available http://iteslj.org/Articles/ Singhal-Internet.html [Accessed: February 20, 2019].

[31] P. Kikilias, D. Papachristos, N. Alafodimos, M. Kalogiannakis, and S. Papadakis, "An educational model for asynchronous e-learning: A case study in a higher technology education," In Proceedings of the International Conference on E-Learning in the Workplace (ICELW09), New York, 2009. https://doi.org/10.3991/ijac.v3i1.987

[32] S. Papadakis, M. Kalogiannakis, M. and N. Zaranis, "Designing and creating an educational apprubric for preschool teachers," Education and Information Technologies, 22 (6), 31473165, 2017. https://doi.org/10.1007/s10639-017-9579-0

[33] R. Romero, T. Zarraonandia, I. Aedo, and P. Díaz,"Designing usable educational material for English courses supported by mobile devices," in HCI in work and learning, life and leisure. USAB. Lecture Notes in Computer Science, vol 6389: G. Leitner, M. Hitz, and A. Holzinge, Eds. Heidelberg, Germany: Springer, 2010, pp-373-368. https://doi.org/10. 1007/978-3-642-16607-5 25

[34] S. Abadi, and F. Saadi, "Exploring Iranian EFL university students' attitudes toward mobile applications for vocabulary learning," International Journal of Language Learning and Applied Linguistics World, 9 (1), 130-142, 2015.

[35] W. Azli, P. Shah, and M. Mohamad,"Perception on the usage of mobile assisted language learning (MALL) in English as a second language (ESL) learning among vocational college students," Creative Education, 9, 84-98, 2018. https://doi.org/10.4236/ce.2018. $\underline{91008}$ 
[36] G. Botero, F. Questier, S. Cincinnato, T. He, and C. Zhu, “Acceptance and usage of mobile assisted language learning by higher education students," Journal of Computing in Higher Education, 30 (2), 426-451, 2018. https://doi.org/10.1007/s12528-018-9177-1

[37] H. Oz, "An investigation of pre-service English teachers' perceptions of mobile assisted language learning," English Language Teaching, 8 (2), 22-34, 2015. https://doi.org/10. $\underline{5539 / \text { elt.v8n2p22 }}$

[38] M. Park,"A task-based needs analysis for mobile-assisted language learning in college ESL contexts," in J. B. Son, Ed., Computer-assisted language learning: Learners, teachers and tools. Newcastle upon Tyne, UK: Cambridge Scholars Publishing, 2014, pp-47-68.

[39] K. Saidouni, and A. Bahloul,“Teachers and students' attitudes towards using mobile assisted language learning in higher education," Arab World English Journal, 3(Special Issue on CALL), 123-140, 2016. https://doi.org/10.2139/ssrn.2822983

[40] E. Soleimani, K. Ismail, and R. Mustaffa,"The acceptance of mobile assisted language learning (MALL) among post graduate ESL students in UKM," Procedia - Social and Behavioral Sciences, 118, 457- 462, 2014. https://doi.org/10.1016/j.sbspro.2014.02.062

[41] M. I. Qureishi, and N. Khan,"A systematic review of past decade of mobile learning: what we learned and where to go," International Journal of Interactive Mobile Technologies, 14(6), 67-81, 2020. https://doi.org/10.3991/ijim.v14i06.13479

[42] S. Bidin, and A. A. Ziden,"Adoption and application of mobile learning in the education industry," Procedia-Social and Behavioral Sciences, 90, 720-729, 2013. https://doi.org/10.1016/j.sbspro.2013.07.145

[43] Y. Suneetha,"MALL (mobile assisted language learning): A paradise for English language learners," International Journal of English Language \& Translation Studies, 1(2), 91-99, 2013.

[44] A. Kukulska-Hulme, and J. Traxler,"Designing for mobile and wireless learning," in H. Beetham, \& R. Sharpe, Eds., Rethinking pedagogy for a digital age: Designing and delivering e-learning, London: Routledge, 2007, pp. 180-192. https://doi.org/10.4324/ 9781351252805-12

[45] R. Muhanna,"Mobile language learning now and in the future," in P. Svensson Ed., Fran vision till praktik: Sprakut bildning och Information steknik (From vision to practice: language learning and IT). Sweden: Swedish Net University, 2011, pp-295-310.

[46] N. D. Bowman, and M. Akcaoglu, "I see smart people!: Using Facebook to supplement cognitive and affective learning in the university mass lecture," The Internet and Higher Education, 23, 1-8, 2014. https://doi.org/10.1016/j.iheduc.2014.05.003

[47] S. McCarthy,"Mobile learning and English language learners. A case study of using iPod touch as a teaching and learning tool," Journal of Interactive Learning Research, 25(3), 373403, 2010.

[48] M. Krüger-Ross, R. D. Waters, and T. M. Farewell,"Everyone's all a-twitter about twitter," in Using social media effectively in the classroom, K. K. Seo, Eds. New York: Routledge, 2012, pp-117-131.

[49] H. Reed,"How mobile technology is changing our culture," Journal of Information Systems Applied Research Systems, 4 (1), 39-48, 2013.

[50] S. J. Warren, and J. S. Wakefield,"Learning and teaching as communicative actions: Social media as educational tool," in Using social media effectively in the classroom, K. K. Seo, Eds. New York: Routledge, 2012, pp- 98-113. https://doi.org/10.4324/9780203118764.ch7

[51] M. Kalogiannakis, M., and S. Papadakis, "Combining mobile technologies in environmental education: a Greek case study,” International Journal of Mobile Learning and Organisation, 11(2), 108-130, 2017. https://doi.org/10.1504/ijmlo.2017.10005249 
[52] S. W. Campbell, and N. Kwak,"Mobile communication and civic life: Linking patterns of use to civic and political engagement," Journal of Communication, 60(3), 536-555, 2010. https://doi.org/10.1111/j.1460-2466.2010.01496.x

[53] A. M. Lin, and A. H. Tong, “Text-messaging cultures of college girls in Hong Kong: SMS as resources for achieving intimacy and gift-exchange with multiple functions," Continuum: Journal of Media \& Cultural Studies, 21(2), 303-315, 2007. https://doi.org/10.1080/1030 4310701278165

[54] A. A. Ziden, M. Rosli, T. Gunasegaran, and S. N. Azizan,"Perceptions and experience in mobile learning via SMS a case study of distance education students in a Malaysian public university," International Journal of Interactive Mobile Technologies, 10 (1), 116-132, 2017. https://doi.org/10.3991/ijim.v11i1.6332

[55] J. A. Arani,"Mobile educational SMSs as supplementary means to teach sentence paraphrasing in EMP course," International Journal of Interactive Mobile Technologies, 11, 45-51, 2016. https://doi.org/10.3991/ijim.v10i1.5188

[56] S. S. Mahmoud, "The effect of using English SMS on KAU Foundation Year students' speaking and writing performance," American International Journal of Social Science, 2(2), 13-22, 2013.

[57] I. S. P. Nation, Teaching and learning vocabulary. New York: Newbury House, 1990.

[58] P. L. Carrell, and J. C. Eisterhold,"Schema theory and ESL reading pedagogy," TESOL Quarterly, 17 (4), 553-573, 1983. https://doi.org/10.2307/3586613

[59] W. Grabe, and F. L. Stoller,"Reading for academic purposes: Guidelines for the ESL/EFL teacher, " in Teaching English as a second or foreign language, M. Celce-Murcia, Eds. Boston, MA: Heinlen \& Heinle Publishers, 2001, pp-187-203.

[60] J. H. Hulstijn, "Retention of inferred and given word meanings: Experiments in incidental vocabulary learning," in Vocabulary and applied linguistics, P. Arnaud and H. Bejoint, Eds. London: MacMillan, 1992, pp-113-125. https://doi.org/10.1007/978-1-349-12396-4_11

[61] S. Rott, "The effect of exposure frequency on intermediate language learner's incidental vocabulary acquisition and retention through reading," Studies of Second Language Learning, 21(4), 589-619, 1999. https://doi.org/10.1017/s0272263199004039

[62] J. Barcroft,"Using retrieval opportunities to increase incidental vocabulary learning during reading: What can be done to support learners in increasing their vocabulary when reading?," Foreign Language Annals, 48(2), 236-249, 2015. https://doi.org/10.1111/flan.12139

[63] K. Cameron, (Ed.). CALL and the learning community. Intellect Books, 1999.

[64] P. Robinson, "Individual differences, cognitive abilities, aptitude complexes and learning conditions in second language acquisition," Second Language Research, 17(4), 368-392, 2001. https://doi.org/10.1177/026765830101700405

[65] . S. P. Nation, Learning vocabulary in another language. New York: Cambridge University Press, 2001.

[66] P. Daftarifard, and N. Bagherpour, General English book: A task-based approach. Tehran: Honar-e Mehregan Publishing, 2018.

[67] B. Plester, C. Wood, and V. Bell,“Txt msg n school literacy: Does texting and knowledge of text abbreviations adversely, " Literacy, 42(3), 137-144, 2008. https://doi.org/10. 1111/j.1741-4369.2008.00489.x

[68] J. K. M. Ali, S. I. Hasnain, and M. S. Beg,"'The impact of texting on standard English: The students' perspective," Arab World English Journal (AWEJ) Special Issue on CALL, 5, 6575, 2019. https://doi.org/10.24093/awej/call5.6

[69] D. Powell, and M. Dixon,"Does SMS text messaging help or harm adults' knowledge of standard spelling?" Journal of Computer Assisted Learning, 27(1), 58-66, 2011. https://doi.org/10.1111/j.1365-2729.2010.00403.x 
[70] M. Tayebinika, and M. Puteh,"Txt msg n English language literacy," Procedia - Social and Behavioral Sciences, 66, 97-105, 2012. $\quad$ https://doi.org/10.1016/j.sbspro.2012. $\underline{11.251}$

[71] L. Verheijen, "The effects of text messaging and instant messaging on literacy," English Studies, 94(5), 582-602, 2013. https://doi.org/10.1080/0013838x.2013.795737

[72] C. Wood, N. Kemp, S. Waldron, and L. Hart,“Grammatical understanding, literacy and text messaging in school children and undergraduate students: A concurrent analysis," Computers and Education, 70, 281-290, 2014. https://doi.org/10.1080/0013838x. $\underline{2013.795737}$

[73] L. Ahmadpour, and M. H. Yousefi, "The role of mobile-assisted language learning on EFL learners' development of writing accuracy, fluency, and complexity," Journal of Modern Research in English Language Studies, 3(4), 105-118, 2016.

[74] L. Kibona, and G. Mgaya, "Smartphones' effects on academic performance of higher learning students. A case of Ruaha Catholic University - Iringa, Tanzania,” Journal of Multidisciplinary Engineering Science and Technology, 2(4), 777-784, 2015.

[75] F.Yavuz, "Do smartphones spur or deter learning: A WhatsApp case study, " International Journal of Educational Sciences, 15(3), 408-415, 2016. https://doi.org/10.1080/ $\underline{09751122.2016 .11890551}$

[76] S. Naz, S., T. Rasheed, and M. Rasheed,"The role of smartphones in learning English: A study of learners' perspectives." In International conference on Research in Humanities, 03, 2019, pp. 17-28.

[77] J. Li, J. Cummins, and Q. Deng, “The effectiveness of texting to enhance academic vocabulary learning: English language learners' perspective," Computer Assisted Language Learning, 30(8), 816-843, 2017. https://doi.org/10.1080/09588221.2017.1366923

[78] F. U. GürocaNa, "Learning vocabulary through text messages: Help or distraction," Procedia-Social and Behavioral Sciences, 232, 623-630, 2016. https://doi.org/10.1016/ j.sbspro.2016.10.086

[79] A. Saricoban, and T. Ozturan,"Vocabulary learning on move: An investigation of mobile assisted vocabulary learning effect over students' success and attitude," EKEV Academic Journal, 17(54), 213-224, 2013.

[80] A. Moura, and A. A. Carvalho,"Mobile learning: Using SMS in educational contexts." In IFIP International Conference on Key Competencies in the Knowledge Society, 2012, pp. 281-291. https://doi.org/10.1007/978-3-642-15378-5_27

[81] M. Saran, K. Cagiltay, and G. Seferoglu, "Use of mobile phone in language learning: Developing effective instructional materials." 5th International Conference on Wireless, Mobile and Ubiquitous Technologies in Education, 2008, 39-43. https://doi.org/10. $1109 /$ wmute.2008.49

[82] M. Lu,"Effectiveness of vocabulary learning via mobile phone," Journal of Computer Assisted Learning, 24(6), 515-525, 2008. https://doi.org/10.1111/j.1365-2729.2008.00289.x

[83] J.H. Hulstijn, and B. Laufer,"Some empirical evidence for involvement load hypothesis in vocabulary acquisition," Language Learning, 51(3), 539-558, 2001. https://doi.org/10. 1111/0023-8333.00164

[84] P. A. Nevills, and P. A. Wolfe, Eds., Building the reading brain, PreK-3. CA: Corwin Press, 2004. 


\section{Authors}

Behnam Behforouz is a Ph.D. candidate of Applied Linguistics at University of Rovira i Virgili, Spain. His interested area of research is Language Education. Email: behnam.behforouz@estudiants.urv.cat

Anca Daniela Frumuselu, Ph.D., is an English Lecturer at Rovira i Virgili University. Her research interests focus on the implementation of modern technological devices in the EFL classroom, e-learning, m-learning and audiovisual translation in second/foreign language learning. She participated various international conferences and she published various articles related to m-learning and to the implication of subtitled audiovisual materials upon colloquial language learning in EFL settings.

Article submitted 2020-09-07. Resubmitted 2020-10-05. Final acceptance 2020-10-05. Final version published as submitted by the authors. 